\section{Behring, Emil Adolf von}

\author{
A. M. Gressner ${ }^{1}$ und O. A. Gressner ${ }^{2}$ \\ ${ }^{1}$ Labor Dr. Wisplinghoff Berlin, Berlin, Deutschland \\ ${ }^{2}$ Labor Dr. Wisplinghoff Köln, Köln, Deutschland
}

Lebensdaten Geboren am 15. März 1854 in Hansdorf (Westpreußen), gestorben am 31. März 1917 in Marburg.

Verdienste Medizinstudium an der Militärärztlichen Akademie des Preußischen Staates (Pépinirè), 1880-1889 Militärarzt in Berlin, ab 1888 am Hygieneinstitut und Institut für Infektionskrankheiten als Assistent von Robert Koch ( $\triangleright$ Koch, Robert, 1843-1910) tätig. Entwicklung und Einführung moderner Methoden der Bakteriologie, Entdecker des
Diphtherie- und Tetanus-Antitoxins, Begründer des Prinzips der passiven Immunisierung (Diphtherie- bzw. TetanusHeilserum). Ab 1895 Professor und Direktor des Hygieneinstituts in Marburg. 1901 erhielt Behring als erster Arzt der Welt den Nobelpreis für Medizin, 1904 Gründung der nach ihm benannten Behring-Werke in Marburg, die Diphtherie- und Tetanus-Seren in großen Mengen produzierten.

\section{Literatur}

von Engelhardt A (1940) Emil von Behring. Chronik seiner Forschungsarbeit und seines Institutes für experimentelle Therapie. (Behringwerk-Mitteilungen; H.10). Bruno Schultz Verlag, Berlin-Grunewald Zeiss H, Bieling R (1940) Behring. Gestalt und Werk. Bruno Schultz Verlag, Berlin-Grunewald 